
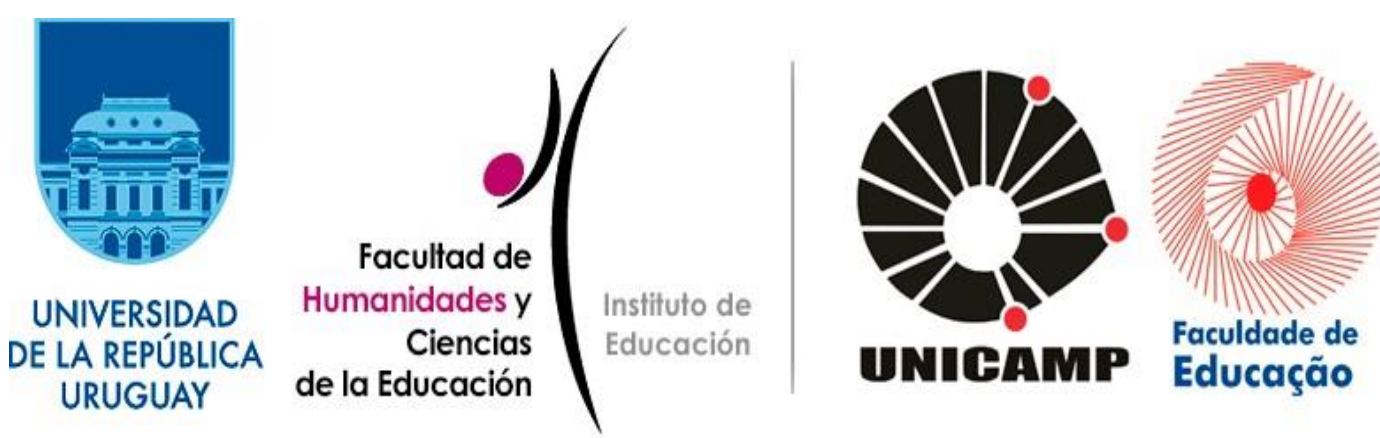

ARTÍCULO | ARTIGO

Fermentario V. 12, $\mathrm{N}^{\circ} 2$ (2018)

ISSN 16886151

Instituto de Educación, Facultad de Humanidades y Ciencias de la Educación,

Universidad de la República. www.fhuce.edu.uy

Faculdade de Educação, UNICAMP. www.fe.unicamp.br

\title{
O Saber Como Fazer: Uma Filosofia Da Orientação A Partir Da Ideia Do Cuidado De Si
}

Saber hacer: una filosofía de orientación a partir de la idea del autocuidado

Paulo Becher Júnior ${ }^{1}$

DOI: https://doi.org/10.47965/fermen.12.2.8

\section{Resumo}

Ao longo do tempo, vinculou-se a ideia de formação com a de conhecimento racional. Na Grécia Antiga, a formação se constituía por uma realidade diversa dessa inferência. Nesse período, o que se buscava era o autoconhecimento. Assim, a filosofia grega propõe, como projeto formativo, a autonomia moral, que passa pelas ideias de preocupação e cuidado de si. A autonomia espiritual, enquanto pensamento livre, é revelador de um modo de vida no qual a sabedoria se apresenta como "saber fazer" e não há uma separação entre o discurso filosófico e a vida cotidiana. No entanto, com o passar do tempo, a formação parece ter se distanciado da vida. Igualmente, parece que a educação e a

\footnotetext{
${ }^{1}{ }^{1}$ Doutorando no Programa de Pós-Graduação em Educação da Universidade Federal de Santa Catarina - UFSC. E-mail: paulinhobecher@gmail.com
} 
ética se desvincularam. A presente proposta de reflexão objetiva, a partir da compreensão da filosofia como um modo de vida, encontrar na reflexão nietzschiana, uma filosofia da orientação em que se encontrem associadas a educação e a moralidade.

Palavras chave: Ética. Formação. Sabedoria. Vida.

\begin{abstract}
Over time the idea of education was linked to knowledge. In Ancient Greece the education was constituted by a reality different from this inference. In this period, what was sought was selfknowledge. Thus, Greek philosophy proposes as a formative project the moral autonomy, which passes through the ideas of concern and self-care. Spiritual autonomy, as a free thought, reveals a way of life where wisdom presents itself as "know-how." Where there is no separation between philosophical discourse and daily life. However, over time, education seems to have distanced itself from life. Equally, it seems that education and ethics have decoupled. The present proposal of reflection seeks, from the understanding of philosophy as a way of life, to find in Nietzschean reflection, a philosophy of orientation where education and morality are associated.
\end{abstract}

Keywords: Education. Ethic. Life. Wisdom.

\title{
1. Introdução
}

Há certa acusação em relação à filosofia. A de que ela seria apenas uma disposição pessoal de alguns indivíduos em relação ao saber. E que essa agradável consideração, fundada em uma amizade pela sabedoria, está desvinculada da realidade. De tal modo, que para tantas pessoas, parece sempre muito difícil encontrar uma finalidade prática para o conhecimento filosófico. Ainda mais, apresentar as suas reais contribuições para a vida do indivíduo enquanto partícipe produtivo do meio social onde está inserido.

Estabelecendo um recorte da presença da filosofia na vida humana, em particular naquilo que diz respeito à educação, muito se entende que a filosofia cumpre o papel de ser o fundamento mais consistente do fazer pedagógico. Ou ainda, é considerada como um eficaz mecanismo para se desenvolver uma pedagogia "mais assertiva" e "mais verdadeira". Em variadas circunstâncias, tantos parecem conferir uma espécie de soberba para a filosofia, na medida em que a entendem como absolutamente esclarecedora e capaz da "verdade última". 
Assim, parece considerar-se o conhecimento filosófico como um efetivo recurso estritamente teórico. De tal maneira, que o seu saber fica encastelado em si mesmo, estabelecendo proposições aparentemente alienadas da relação pedagógica de formação e ensino do ponto de vista prático. E por assim dizer, se torna tão somente um discurso. Tal consideração pode deixar transparecer um suposto distanciamento entre filosofia, vida e educação. Cabe aqui, então, questionar-se: é certo então que a filosofia sempre foi distante da vida? Em que medida a filosofia ainda pode contribuir para o processo pedagógico, subsidiando uma perspectiva humanizadora da sua realização? Quais propostas podem ser encontradas para se estabelecer um fundamento ético para a educação, a partir das contribuições do modo nietzschiano de operar com a filosofia?

Tencionar as possibilidades de respostas para tais questionamentos é a aspiração do presente estudo. Dessa forma, buscar-se-á fazê-lo, tendo a filosofia antiga como premissa inicial assim como Pierre Hadot a considerava. E ainda, suscitar da filosofia possibilidades pedagógicas que venham ao encontro das interpelações aqui apresentadas. Por fim, garimpar em Nietzsche possibilidades de encontrar no seu pensamento uma "filosofia da vida", e dela um modo de orientação. De tal maneira, que seja possível entender que as coisas "que são", podem ser tratadas de "outra maneira".

Esta reflexão bibliográfica, de valor heurístico, assume metodologicamente a condição de ensaio e é parte integrante de pesquisas junto ao Grupo de Estudos Biografia Nietzsche, vinculado ao Programa de Pós-Graduação em Educação da Universidade Federal de Santa Catarina, o qual vislumbra a possibilidade de se operar com uma pedagogia em Nietzsche, dando destaque a uma filosofia da orientação.

\section{A filosofia como modo de vida e a ética da existência}

"O sophós é aquele que sabe muitas coisas, que viajou muito, ou o que sabe se conduzir bem na vida e é feliz?” (Hadot, 2014: 39). Este questionamento elaborado por Pierre Hadot (1922-2010) apresenta “o saber" com o sentido de "saber fazer". Com isso, o autor aponta para o direcionamento da compreensão da filosofia como um modo de vida operativo. E não um discurso estritamente conceitual. Também nele, parece possível encontrar o nexo entre a filosofia e a educação, segundo a perspectiva aqui assumida e anteriormente apresentada.

A sabedoria é tomada em uma perspectiva factual. Apresenta-se como "capaz de transformar completamente o modo de ser, de ver o mundo e a personalidade daquele que ama o saber" ${ }^{2}$. Pode-se falar que se trata de uma vida filosófica, na qual há uma influência direta entre o que se pensa e o que

\footnotetext{
2 Júnior, 2017: 145.
} 
se vive, buscando unir pensamento e vida. A ideia de "saber fazer", dessa forma, apresenta a sabedoria como um modo de orientação formativa que impacta na vida concreta do sujeito, e não simplesmente habita os seus pensamentos.

A Filosofia Grega Antiga era dotada de uma condição na qual os diálogos, sejam eles orais ou escritos, parecem sempre demonstrar que a relação pedagógica entre o mestre e os discípulos buscava açodar uma resposta para um questionamento concreto. Primordialmente, se apresenta como uma "relação viva entre pessoas, em vez de uma relação abstrata com ideias"3. Por assim se constituir, a filosofia na Antiguidade mostra que o lugar para se pensar é o cotidiano, inclusive o da escola. A filosofia não era e não precisa ser na atualidade somente teórica. Aqui se faz pertinente, destacar a importante reflexão sobre o afastamento ou não da pesquisa filosófica atual em relação aos problemas culturais de agora, apresentada por Viesenteiner (2018: 23), que dentre outras coisas destaca: "Em suma, a pesquisa em filosofia pode sem problemas conjugar engajamento e rigor conceitual. Ela não precisa encerrar-se intramuros universitários, nem deixar-se cooptar por agendas”. Desta maneira, igualmente, se estabelece uma forma de aplicação prática do pensamento filosófico na existência cotidiana.

Desde já, se faz necessário lembrar, que a compreensão da Filosofia Antiga apresentada por Hadot, sustenta uma proposta ética e política. É um modo de vida, o qual não se apresenta como uma característica marginal ou secundária do agir humano. A filosofia, pode-se dizer, atua como um mecanismo de orientação da vida e o filósofo a tem como seu critério de vida prática e não como um acessório do seu pensamento. "Mas tudo o que faz fá-lo sempre com a filosofia. Esta é seu alimento de cada dia..."4 . O labor terapêutico da vida se dá através da reflexão filosófica e também, do modo filosófico de encarar os ditames da existência.

Na compreensão do autor francês, Sócrates, por exemplo, merece destaque especial nesse plano. Isso por que, este filósofo parece nunca apresentar um distanciamento entre o pensar e o agir. De outro modo, Sócrates foi "o primeiro filósofo a pôr a 'vida' (bios) enquanto sua principal pergunta"5. Nele, segundo Hadot, é possível considerar que a filosofia perpassou todos os aspectos da sua vida. Foi a partir dela que Sócrates se posicionou frente à cultura, à política e à religião ateniense do seu tempo. Nesse filósofo, se encontra "uma sabedoria que excede em muitos aqueles que a procuram, que nunca encontra termo, mas que é capaz de transformar completamente o modo de ser, de ver o mundo e a

\footnotetext{
${ }^{3}$ Hadot, 2016: 79.

${ }^{4}$ Platão, 2013: 87.

${ }^{5}$ Júnior, 2016: 351.
} 
personalidade daquele que ama o saber"6 . Assim, é possível inferir que a imagem do Sócrates filósofo deixa transparecer a silhueta de alguém que encontrou na filosofia um modo de pensar e agir, ou seja, um modo de orientação da vida.

A maneira como se considera a sabedoria na antiguidade nesses termos, pode estabelecer um interessante diálogo com a educação. A partir do instante em que se abre a perspectiva de uma espécie de melhoramento da vida, tendo o agir ético como ponto de partida, se deixa transparecer a função pedagógica da ética em relação à vida. Hadot postula a filosofia como uma "prática voluntária, pessoal, destinada a operar uma transformação do indivíduo, uma transformação de si"7. Então, o que se realiza é um exercício com o objetivo de o sábio aprender a "se conduzir bem na vida", como sugere o questionamento inicial desta reflexão.

Assim sendo, o artifício proposto por esta compreensão da sabedoria, pode apresentar a formação como a arte da existência. Na qual, mais uma vez, transparece a condição da filosofia de não ser apenas teórica, pois coloca o próprio indivíduo como problema de investigação. “Opera-se nele uma tomada de consciência de si; ele se põe a si mesmo em questão”. (Hadot, 2014: 56.). Problemática ética, que leva o indivíduo a ocupar-se de si mesmo, buscando estabelecer os fundamentos através dos quais vai direcionar o seu modo de vida. Também demonstra que se a reflexão filosófica assumiu essa condição, tal intento demonstra o caráter orientador que ela assumiu enquanto mecanismo formativo.

Em favor desse modo filosófico de condução da vida, que apresenta um vínculo entre o que "se pensa" com o que "se vive" de modo que não haja separação entre estas realidades, característica presente na filosofia antiga, pode encontrar em Sócrates um ícone significativo dessa sabedoria que opera com a vida prática. Neste sentido, parece oportuna a declaração presente na I Parte da “Apologia de Sócrates”, na qual se lê:

E é por isso, por obediência ao deus, que ainda continuo essa busca, investigando cidadãos e estrangeiros que suponho sábios. E quando não encontro a sabedoria esperada, lhes mostro, como servidor do deus, que não são sábios. Por causa dessa ocupação, não tenho tido tempo de atender aos deveres públicos nem às necessidades da minha família. Os serviços prestados ao deus me levaram à extrema pobreza. Entretanto, enquanto me dedico a essa atividade, muitos jovens com tempo livre, pois são filhos de famílias ricas, me acompanham por sua própria vontade e parecem sentir grande prazer em observar como examino os homens. Muitas vezes eles me imitam e tentam examinar aqueles que encontram. E acredito que encontrem muitos

\footnotetext{
${ }^{6}$ Id. 2017: 145.

${ }^{7}$ Hadot, 2016: 115-116.
} 
homens que pensam muito saber, mas que pouco ou nada sabem. Em consequência, todos os que são examinados se enfurecem com eles e também comigo, dizendo que Sócrates é um imundo que corrompe os jovens. Mas se alguém lhes pergunta o que ele faz ou o que ensina, não sabem responder. Então, para que não pareçam tolos, dizem aquelas coisas banais que geralmente se diz dos filósofos: "que ele especula sobre as coisas do céu e da terra, que não acredita nos deuses e faz argumentos frágeis parecerem fortes". (Platão, 2009: 26).

A intenção aqui não é a de incentivar uma ação individual que traga qualquer tipo de ônus para outros ou para a sociedade. O referencial formativo do pensamento socrático revela que sua atividade de examinar as pessoas o levou a deixar outras ações valorizadas pela sociedade daquele instante, e até mesmo, algumas das suas responsabilidades familiares. Ao que aqui se busca dar relevo é para o fato de a sabedoria, enquanto modo de condução da vida, se encontrar no ato de examinar a própria existência. Bem como, na possibilidade de levar o outro para o exame da sua própria vida. Como não há uma separação entre aquilo que se pensa e aquilo que se vive, "na filosofia antiga o discurso filosófico não tem autonomia num plano teórico separado, podendo ser compreendido apenas no contexto de uma opção existencial"8.

O sentido apresentado pela Filosofia Antiga para a categoria sabedoria se sustenta na ideia de transformação, ao que os filósofos antigos nomeavam como psicagogia, isto é, a transformação do sujeito. A filosofia enquanto modo de vida se apresenta como uma forma de viver melhor, daí o caráter ético da formação. É uma espécie de enfrentamento de si, na perspectiva da "superação de si mesmo". A filosofia da educação desvelada com o mundo grego antigo demonstra o caráter imprescindível do diálogo com a realidade, como pressuposto da formação. Esta se constituía com o intento de responder a uma real necessidade do indivíduo ou da sociedade.

De certa maneira, a escola que transparece com a Filosofia Antiga não é uma escola de conteúdos, mas sim, de uma ação ética de quem não apenas fala sobre a verdade, por exemplo, mas a vive. $\mathrm{O}$ filósofo ou mestre, presente na antiguidade filosófica grega, possui uma coerência entre a fala e a ação.

Nesse instante, é possível o seguinte questionamento: nos tempos atuais, a ética está presente na educação como um dos seus fundamentos? A ação pedagógica ainda é capaz de levar os seus agentes a "questionar a si mesmo e os valores que dirigem nossa própria vida?" . O que aqui está se colocando

\footnotetext{
${ }^{8}$ Júnior, 2016: 351.

${ }^{9}$ Hadot, 2014: 55.
} 
em xeque é a possibilidade da educação de ainda levar o indivíduo a ocupar-se a si mesmo, possivelmente com o intuito de tornar a sua vida mais consciente e autêntica.

Na disposição de continuar dialogando, sem buscar obrigatoriamente um ponto final, poder-se-á recorrer à perspectiva filosófica sustentada com as ideias de Nietzsche. Quando dela se busca depreender uma filosofia da orientação, parece possível a continuidade da reflexão a respeito da filosofia como um modo de vida; bem como identificar os aportes formativos ou educacionais que nela podem ser encontrados.

\section{Das ideias de Nietzsche, uma filosofia da orientação}

Friedrich Nietzsche (1844-1900) habitualmente não é apresentado como um pensador capaz de sustentar uma proposta ético-formativa. Isso porque, tantas vezes é considerado como o "filósofo do martelo", que acabou por apresentar um niilismo absoluto. Ele coloca, no seu horizonte reflexivo, questionamentos em relação à moral e à cultura, de modo que, tantas vezes, foi taxado como um irracionalista, como alguém que negou o sujeito; ou tendo a condição de "filósofo da vida", se apresentou como um absoluto metafísico. Tal consideração se apresenta em afirmativas onde se lê que “em conformidade com todo o pensamento do Ocidente desde Platão, o pensamento de Nietzsche é metafísica”. (Heidegger, 2014: 642.).

Não há que se fazer uma apologia a Nietzsche, nem mesmo buscar categorizá-lo dentro de um tempo ou de uma escola filosófica. No entanto, a operação nietzschiana da filosofia, sustentada no perspectivismo, pode abrir possibilidades formativas pertinentes. Segundo Marques (2003: 09.) “a característica mais fundamental do pensamento filosófico da época moderna até nossos dias é seu perspectivismo, e Nietzsche é o autor que radicalizou até um extremo limite essa mesma característica”. Desta forma, parece possível derivar do pensamento nietzschiano uma filosofia da orientação, tendo-o compreendido no sentido de fazer da filosofia um modo de vida.

A biografia de Nietzsche demonstra o quanto enfrentou momentos de doenças. Saúde foi em diversos instantes algo de que muito careceu, mas ele mesmo relata que ao longo dos seus muitos momentos de enfermidade, alguns desses sem mesmo aparentemente ter uma causa orgânica, buscou enfrentar estas condições e dela buscar uma maneira de superação. E justamente pelo fato de enfrentar momentos de extrema dureza, se tornou capaz de questionar e desautorizar valores dados como absolutos, ao mesmo tempo, que buscava estabelecer outros.

Da ótica do doente ver conceitos e valores mais sãos, e, inversamente, da plenitude e certeza da vida rica descer os olhos ao secreto lavor do instinto de decadence - este 


\begin{abstract}
foi o meu mais longo exercício, minha verdadeira experiência, se em algo vim a ser mestre, foi nisso. Agora tenho-o na mão, tenho mão bastante para deslocar perspectivas: razão primeira porque talvez somente para mim seja possível uma "tresvaloração dos valores". (Nietzsche, 2005: 22.).
\end{abstract}

Nesse horizonte, é possível verificar que a vida se apresentou como integrante da ação prática do filósofo, ela se tornou objeto do pensar sem haver oposição ou segmentação entre ambos (vida e pensamento). Nela e, através dela, existiu uma ocupação consigo mesmo, capaz de transformar a sua própria pessoa. Em alguma medida, a vida orientou para a descoberta de si, ao mesmo tempo em que impulsionou uma forma peculiar e autêntica de pensar, associada ao agir. Isso fez do saber um agir, ou melhor, um "saber como fazer" diante da vida.

\begin{abstract}
De fato, assim me aparece agora aquele longo tempo de doença: descobri a vida e a mim mesmo como que de novo, saboreei todas as boas e mesmo pequenas coisas, como outros não as teriam sabido saborear - fiz da minha vontade de saúde, de vida, a minha filosofia... pois atente-se para isso: foi durante os anos de minha menor vitalidade que deixei de ser um pessimista: o instinto de auto-restabelecimento proibiu-me uma filosofia da pobreza e do desânimo. (Nietzsche, 2008: 23.).
\end{abstract}

A falta de saúde e a "vontade de vida" podem ser em Nietzsche fatores orientadores para se posicionar em relação à existência. Filosofia e vida se fundem nesse processo que busca de alguma maneira dar conta da vivência. A "grande saúde" de que trata Nietzsche parece ter dentro dela a presença da doença, de modo que a decadência da vida por falta de saúde faz aparecer particularidades, toques individuais, enfim: nuances reveladoras de um modo aparentemente mais autêntico de ver a própria vida e tudo o que está ao seu entorno. A perspectiva, enquanto forma nietzschiana de propor a filosofia, não é exclusivamente um conceito, também é uma maneira de orientar as escolhas e surge com o intuito de responder a uma questão vivencial concreta. A saber, o enfrentamento da falta de saúde a partir de uma "vontade de vida".

Nietzsche se mostra ocupado consigo mesmo e prima pelo cuidado de si, de modo que a sua filosofia não se caracteriza por um pensamento insólito. Ao contrário disso, é o modo por meio do qual se enxerga a vida e como são enfrentadas as dificuldades, não com uma atitude de tibieza. De outro modo, é uma busca por transpor e superar os limites que lhe são impostos, tendo uma atitude positiva frente à própria realidade. No aforisma 618 de Humano, Demasiado Humano se encontra a seguinte consideração: "Habitualmente nos empenhamos em alcançar, ante todas as situações e acontecimentos da vida, uma atitude mental, uma maneira de ver as coisas - sobretudo a isto se chama ter espírito filosófico"10. Assim, a filosofia se constitui como uma "filosofia da orientação". Com a atitude

\footnotetext{
${ }^{10}$ Nietzsche, 2005: 261.
} 
filosófica, Nietzsche parece encontrar a saúde necessária para continuar fruindo a vida. "Tomei a mim mesmo em mãos, curei a mim mesmo"11.

Nietzsche não parece ter apenas boas ideias e um fino trato na escrita para tratar da problemática humana. Ele parece utilizar da filosofia para ser o seu dispositivo perante a vida e é por meio dela que orienta a sua trajetória, tendo a sua própria realidade existencial como a questão filosófica por excelência, de modo que a sua própria biografia serviu como um mecanismo pedagógico, o quel parece ter superado os próprios parâmetros de uma educação institucionalizada. Nietzsche encontra na sua própria vida os ditames que orientaram o seu crescimento pessoal, e até mesmo a sua atitude positiva frente à vida. De algum modo, a filosofia parece ter conectado a pessoa de Nietzsche com o seu pensamento. Dessa fusão, surge um propositor afirmativo da vida, que consegue ocupar-se de si mesmo, curando as suas feridas, a ponto de "tresvalorar" os valores estabelecidos, apresentando uma vida que logrou êxito.

\begin{abstract}
Um homem que vingou faz bem aos nossos sentidos: ele é talhado em madeira dura, delicada e cheirosa ao mesmo tempo. Só encontra sabor no que lhe é salutar; seu agrado, seu prazer cessa, onde a medida do salutar é ultrapassada. Inventa meios de cura para injúrias, utiliza acasos ruins em seu proveito; o que não o mata o fortalece. De tudo o que vê, ouve e vive forma instintivamente sua soma: ele é um princípio seletivo, muito deixa de lado. Está sempre em sua companhia, lide com homens, livros ou paisagens: honra na medida em que elege, concede, confia. Reage lentamente a toda sorte de estímulo, com aquela lentidão que uma larga previdência e um orgulho conquistado nele cultivaram - interroga o estímulo que se aproxima, está longe de ir ao seu encontro. Descrê de "infortúnio" como de "culpa": acerta conta consigo, com os outros, sabe esquecer - é forte o bastante para que tudo tenha de resultar no melhor para ele. (Nietzsche, 2008: 23-24.).
\end{abstract}

O que acima se pode constatar é uma espécie de itinerário de condução da existência, no sentido do seu crescimento e conservação. A experimentação da realidade concreta da vida molda um estilo e faz surgir características no indivíduo. Por exemplo, a capacidade de optar por aquilo que é útil e favorável para preservar a saúde e a vida. Já, aquilo que não se propõe a resguardar a vida não serve, então, opta-se por aquilo que vivifica. "Vontade de vida" é então, um critério para se estabelecer aquilo que convém ou não para o indivíduo. De certo modo, uma vida que vingou se apresenta como uma vida onde se fazem escolhas, a partir de critérios que favorecerão a vida prazerosa e saudável. Pode-se intuir, igualmente, a presença de uma "ocupação consigo mesmo". O indivíduo desenvolve meios para superar as dificuldades, ao inventar "meios de cura". Daquilo que em um primeiro

\footnotetext{
${ }^{11}$ Id. 2008: 23.
} 
momento pode ser entendido como uma dificuldade que fere, é possível encontrar algo que fortaleça a pessoa. De algum modo toda a realidade circundante da pessoa o impacta, a forma e a conduz. Nada parece estar alheio a sua formação, ao seu processo de "talhar" a si mesmo. Uma vida que vingou, também, presume um sujeito que está sempre "em sua companhia". Não se esquece de se observar, de estar atento em relação àquilo tudo que vem ao seu encontro, ou que lhe é possível experimentar.

O ser humano para quem a vida deu frutos (vingou) é seletivo. Parece que aceitar tudo, firmar-se em todas as posições, concorrer em favor de todas as causas não é uma forma de prosperar. Abandonar algumas situações, deixar de lado algumas coisas, fatos ou até pessoas, é uma forma de cultivo, é um exercício do "cuidado de si”. Aparentemente, nem tudo é proveitoso ou adequado. Para tanto, como realizar tudo isso sem estar atento em relação à vida de uma forma geral, e a si mesmo de uma maneira particular? A seletividade se apresenta como um postulado do cultivo de si.

Nas palavras de Nietzsche acima apresentadas é possível ainda considerar a importância da "paciência". Não correr apressadamente ao encontro de todos os "estímulos" é uma forma de preservação. "Interrogar", isto é, questionar aquilo que vem de encontro ao "eu" é um fator que possibilita o "cuidado de si”. Não é a mesma coisa que ser leniente, é dar tempo para ser previdente. Uma vida que vingou, por fim, é uma existência na qual não apenas se reage. "Outra prudência e autodefesa consiste em reagir com a menor frequência possível" ${ }^{12}$. De outro modo, é uma condição de vida que busca construir aquilo que é favorável para si, na medida em que possibilita o seu crescimento pessoal.

O filósofo alemão apresenta critérios orientadores da existência que visam a um modo de vida, que se pode dizer, saudável, ou seja, propõe condições positivas para formar e desenvolver situações de crescimento para o ser humano. Esta leitura de Nietzsche, por sua vez, parece demonstrar a possibilidade de se configurar uma Filosofia da Orientação a partir da ideia do "cuidado de si". Segundo Stegmaier (2013), “os indivíduos tornam-se pragmática e moralmente soberanos, se estão firmemente sentados sobre si mesmos"13.

\section{Considerações finais}

A Filosofia Antiga se constitui como um modo de vida que é sustentado por uma teoria. Portanto, a reflexão filosófica perpassa todas as esferas da vida do indivíduo, tornando-se o seu mecanismo para encarar a existência. Dessa maneira, pode-se sugerir que o processo de formação se realiza também

\footnotetext{
${ }^{12}$ Nietzsche, 2008: 45.

${ }^{13}$ Stegmaier, 2013: 318.
} 
fora dos espaços institucionalizados. Esse modo filosófico de enfrentar a vida a configura não apenas como um discurso, mas também como uma atividade concreta. Busca viver na realidade prática aquilo que se aprendeu como verdadeiro em uma teoria. "O Verdadeiro saber é, finalmente, um saber- fazer, e o verdadeiro saber-fazer é um saber-fazer o bem"14.

A ideia de sabedoria parece ter perdido o sentido de transformação de uma forma de vida, a partir do "cuidado de si", apresentado na antiguidade. O que certamente continuou é a sua identificação como saber racional. Tal fato pode ter acontecido pela condição da filosofia, ao longo do tempo, de ter sido submetida à teologia (Idade Média), depois à ciência (Modernidade) e à tecnologia (Atualidade). Os gregos possivelmente intentaram, a partir da filosofia como um "modo de vida" e um "cuidado de si", realmente formar sujeitos para dar conta das questões práticas da vida à luz do saber filosófico. Sua operação filosófica sugere um exercício espiritual em vistas de transformar a subjetividade.

Nessas condições, a filosofia enquanto "forma de vida" ajuda a viver melhor. A precariedade da vida, condição da existência ainda mais evidente diante dos problemas dos dias atuais, postula um exame da vida com mais acuidade. Assim, o discurso filosófico parece não bastar. Dele, se constitui uma prática, há uma busca por coerência de aplicação que vincula discurso e a ação. Dessa forma, o papel pedagógico da ética apresentado na filosofia grega antiga, é o de propor uma educação que não apenas privilegie o discurso filosófico, mas que também constitua um modo de operar de maneira concreta no mundo.

A ética, pode-se dizer, é uma forma de vida que vislumbra a transformação do "eu". Parece não haver ética sem o trabalho sobre si. Como o professor é um pouco daquilo que ensina, o mestre aparece como um modelo de vida. O seu modo de vida considera elementos pessoais, um "phatos" (sentimento) e um "ethos" (espaços públicos de ação). Desse modo, sua atividade ética, realizada no espaço social, pode ser entendida como um "cuidado de si" e um "cuidado dos outros".

A inserção do mestre no espaço formativo é discursiva, porém, seu discurso parece que não é pronto. O mestre é atopos, estranho em relação à realidade, na medida em que não se conforma com a mesma, e busca transformá-la. A formação desenvolvida com a filosofia antiga não sugere a neutralidade. Ao contrário, seu fulcro está na "transformação de todo o modo de ser daquele que a pratica, mais do que a formulação de doutrinas e sistema de pensamentos”. (Júnior, 2016: 380).

Os juízos apresentados sugerem importantes movimentos para a educação. No contexto social da atualidade, postula-se examinar a vida humana em todos os seus aspectos. Considerando que um dos

\footnotetext{
${ }^{14}$ Hadot, 2016: 39.
} 
grandes desafios do ser humano é o de ocupar-se consigo mesmo e com o mundo que o rodeia, a educação enquanto movimento formativo da alma humana pode encontrar na filosofia, um "modo de vida" que oriente a trajetória vital do indivíduo ensinando-o a "saber fazer" o bem, tanto para si próprio quanto para o outro.

Na esteira desse desenvolvimento, aparece um discurso não conformado com a realidade, aí nos deparamos também com a filosofia de Nietzsche. Este, por sua vez, buscou uma reformulação da moral, ainda que tantas vezes seja considerado como um autor amoral. Friedrich Nietzsche parece destacar a força das possibilidades formativas encontradas na realidade da vida, no que diz respeito ao erro e as situações limitadoras. E dentro dela, ressaltar a necessidade de se realizar um "cuidado de si" e uma “inquietação de si”. Neste direcionamento, se apresentam as palavras do próprio filósofo:

\begin{abstract}
No meu tempo na Basiléia, toda a minha dieta espiritual, a divisão do dia incluída, era um desperdício sem sentido de forças extraordinárias, sem cuidar de uma provisão para cobrir o consumo, sem mesmo refletir sobre consumo e compensação. Faltava um sutil 'cuidado de si', a tutela de um de um instinto imperioso, era nivelarse a qualquer um, uma 'ausência de si'. (Nietzsche, 2008: 37.).
\end{abstract}

A "vontade de vida" que se apresentava nos momentos de "falta de saúde" levou Nietzsche a conduzir a sua vida a partir dos momentos de penúria. Neles, o filósofo foi capaz de forjar a si mesmo, revelando possibilidades formativas oriundas da sua própria relação com a doença e o desejo de saúde, de tal modo, que considera que a sua filosofia se constrói a partir destas experiências. Elas lhe garantem a construção da sua individualidade, tendo proposições positivas em relação à vida.

A relação de Nietzsche com os fatos da sua vida sugere uma Filosofia da Orientação. Tal empreendimento parece levá-lo a preocupação de efetivar um cuidado para consigo mesmo, no intuito de aprender a identificar e valorizar aquilo que vivifica, ou seja, a considerar as perspectivas que contribuem para o cultivo da sua própria vida. Nelas estão presentes: o prazer, a seletividade e a paciência, enquanto fatores que sustentam um modo de vida, que na avaliação do autor é uma pessoa que "vingou".

Em certa medida, ao olhar para a doença, Nietzsche encontra condições de sabedoria não estritamente como saber racional. Antes disso, saúde e doença se apresentam como fatores de ampliação da vida e do próprio saber. Se for fato que a doença trouxe razão (sabedoria) para Nietzsche, como ele pode inspirar outros a lidar com essa realidade? Quais “doenças" presentes na escola e nos processos pedagógicos poderiam ampliar a formação e a vida? Quais lições delas são possíveis? 
Na perspectiva nietzschiana, com o enfrentamento da enfermidade, surge a possibilidade da cura da vida e, ainda, a condição de se estabelecer valores. Pensar, aprender durante as situações de penúria é uma proposta orientadora possível na Filosofia de Nietzsche. Se "ter nas mãos" (cuidado e ocupação de si) é uma forma de retomar o que não está certo. "Quando as coisas resultam mal, perde-se muito facilmente o olho bom para o que se fez... honrar mais dentro de si o que dá errado... isto sim está de acordo com minha moral" ${ }^{15}$. O erro pode ser um marco de orientação. A possibilidade pedagógica do erro se monstra ainda muito insipiente na prática pedagógica atual, nela abomina-se a dificuldade e quase sempre se foge do erro. Nietzsche parece fazer deles um processo filosófico de orientação.

A escola de uma forma geral parece não lidar bem com a questão do erro enquanto possibilidade de aprendizado. A biografia de Nietzsche demonstra que nem tudo "deu certo". No entanto, dessas situações de agruras, foi possível orientar a vida a partir do "cuidado de si". Os dissabores presentes no cotidiano escolar facilmente caem na vala comum da lamúria e da falta de estímulo. Em que medida o erro pode ajudar discípulo e mestre a acertarem?

Por fim, a filosofia possui a dimensão prática dela tantas vezes requisitada como um "modo de vida" pode conduzir as ações dos indivíduos. Tanto na leitura da filosofia antiga sugerida por Hadot, quanto na operação filosófica de Nietzsche, a vida na sua realidade se apresenta como mote formativo. Nesses dois exemplos, a filosofia atuou como instrumento de análise e de ação. Encastelar-se sobre si mesma parece não ser a melhor alternativa para a reflexão filosófica, correndo o risco de ela mesma $\operatorname{adoecer}^{16}$.

Na atual conjuntura social e escolar, a orientação de se manter sempre no movimento para se reorientar parece ser uma premente necessidade filosófica, pedagógica e formativa. A filosofia enquanto um "modo de vida" pode revelar que tudo é, pode ser diferente.

\section{Referências}

Dutra, J.da C. y Goto, R. (Org.). (2018) O filosofar hoje, na pesquisa e no ensino da filosofia. Blumenau: IFC.

Hadot, P. (2014) O que é a filosofia antiga?. São Paulo: Loyola.

. (2016) A filosofia como maneira de viver: entrevistas de Jeannie Carlier e Arnold I. Davidson. São Paulo: É Realizações.

Heidegger, M. (2014). Nietzsche. Rio de Janeiro: Forense.

Júnior, G.M. de A. (2016) Atopía em Pierre Hadot (parte 1). Em: Archai, N. 18, Coimbra, 347- 386.

\footnotetext{
${ }^{15}$ Nietzsche, 2008: 33.

16 “La filosofía se ha convertido en un discurso encerrado en sí mismo...”. (Genis, Andrea Díaz in Dutra, 2018: 77.).
} 
(2017) Atopía em Pierre Hadot (parte 2). Em: Enunciação, 2(1), Rio de Janeiro, 141-157.

Marques, A. (2003) A filosofia perspectivista de Nietzsche. São Paulo: Discurso Editorial; Editora UNIJUÍ.

Nietzsche, F. (2008). Ecce Homo. São Paulo: Companhia das Letras. (2005). Humano, demasiado humano. São Paulo: Companhia das Letras.

Platão. (2009) Apologia de Sócrates; O Banquete. São Paulo: Martin Claret. (2013) Carta VII. Rio de Janeiro. Loyola. São Paulo: Ed. PUC-Rio.

Stegmaier, W. (2013) As linhas fundamentais do pensamento de Nietzsche. Petrópolis:Vozes. 